\title{
AS EXPERIÊNCIAS CORPORAIS E DE MOVIMENTO DE BEBÊS NA EDUCAÇÃO INFANTIL
}

\author{
Vanessa Bruxel Schmitz ${ }^{1}$, Silvane Fensterseifer Isse ${ }^{2}$
}

\begin{abstract}
Resumo: Esta pesquisa tem como objetivo investigar como ocorrem as experiências corporais e de movimento de bebês na Educação Infantil. Trata-se de uma pesquisa-ação realizada em uma Escola Municipal de Educação Infantil. Foram desenvolvidas aulas de Educação Física/ intervenções semanais, em diferentes espaços físicos da escola, envolvendo a utilização de diversos materiais. Para a coleta de informações, realizaram-se observações, registros em diário de campo e filmagens. A investigação evidenciou a necessidade de desafios e experiências diversificadas; porém, sem esquecer o respeito às individualidades e emoções demonstradas pelos bebês durante as atividades, além de refletir e organizar os espaços. A participação e a orientação do professor inserido nesse contexto são, para as crianças, um norteador no desenvolvimento das aulas.
\end{abstract}

Palavras-chave: Experiências Corporais; Bebês; Educação Infantil.

\section{THE BODY AND MOVEMENT EXPERIENCES FROM BABIES IN PRESCHOOL}

\begin{abstract}
This research has the aim of investigating how body experiences and baby movements happen in preschool. It is an action-research held in a Public Preschool. Weekly physical education classes were developed in different places of the school, involving the use of several materials. To collect information, observations, records and filming were made. The investigation showed the need of diversified challenges and experiences; however, not forgetting to respect the individuality and emotions showed by the babies during the activities, besides reflecting and organizing the spaces. The participation and orientation of the teacher inserted in this context are the guiding for the kids.
\end{abstract}

Keywords: Body experiences, Babies, Preschool.

\section{INTRODUÇÃO}

A Educação Infantil é caracterizada como a primeira etapa da Educação Básica, considerada fundamental à vida das crianças. Muitas vezes, elas passam a maior parte

1 Licenciada em Educação Física pelo Centro Universitário UNIVATES.

2 Doutoranda em Ciências do Movimento Humano pela UFRGS. Docente do Centro de Ciências Humanas e Sociais do Centro Universitário UNIVATES. 
do seu dia nas escolas de Educação Infantil; logo, é importante que estas sejam um ambiente acolhedor, contribuindo, dessa forma, para o crescimento e o desenvolvimento humano. É um trabalho de parceria entre as crianças, pais, profissionais e a sociedade.

A Educação Infantil tem como tarefas proporcionar aos bebês o maior número possível de experiências de movimento, experimentação, troca de experiências e ampliação das relações sociais e do ambiente. As experiências corporais de movimento, individuais ou coletivas, numa perspectiva lúdica do corpo, permitem à criança descobrir, descobrir-se, desenvolver sua independência e amadurecimento que fomentam sua curiosidade. De acordo com o Referencial Curricular Nacional para Educação Infantil (BRASIL, 1998, p. 13), "a qualidade das experiências oferecidas podem contribuir para o exercício da cidadania, respeitando-se as especificidades afetivas, emocionais, sociais e cognitivas das crianças de zero a seis anos”.

O corpo, na infância, é elemento fundamental para o desenvolvimento das crianças. Ele é considerado a primeira forma de linguagem, pois, através dele, elas introduzem sua comunicação com o meio, expressam sentimentos, emoções, exploram o ambiente e partem em busca do que lhes desperta interesse e curiosidade, experimentando sempre diferentes maneiras de utilizar o corpo. Por conseguinte, necessitam descobrir, explorar, conhecer e vivenciar o novo, e o corpo está diretamente relacionado a essas vivências. Fonseca (2008, p. 410) afirma que:

O corpo surge, portanto, mais uma vez, como o componente material do ser humano, que, por isso mesmo, contém o sentido concreto de todo o comportamento sócio histórico da humanidade. O corpo não é, assim, o caixote da alma, mas o endereço da inteligência. $\mathrm{O}$ ser humano habita o mundo exterior pelo seu corpo, que surge como um componente espacial e existencial, corticalmente organizado, no qual e a partir do qual o ser humano concentra e dirige todas as suas experiências e vivências.

A experiência corporal abre caminho para a criança desenvolver sua independência, consciência própria e individualidade para o amadurecimento cognitivo. A partir dessas experiências (corpo), estabelece-se também a possibilidade de fomentar a curiosidade, buscar o novo (novos conceitos), sentir o movimento para modificá-lo e dar-lhe um novo significado, dentro de sua condição, tanto de movimentar-se quanto, social e culturalmente, expressar-se, dialogando com o mundo (BAECKER, 2001).

O professor desempenha uma função essencial nessa experimentação do corpo. O papel e a importância das aulas de Educação Física, nesse contexto, devem-se ao fato de que, através dessas experiências, geram-se situações por meio das quais as crianças podem criar, inventar, descobrir movimentos novos, reelaborar conceitos e ideias sobre o movimento e suas ações.

As aulas de Educação Física para bebês têm sido pouco exploradas no Campo da Educação Física Escolar, como também restrita a produção científica sobre o tema. Esses fatos motivaram a realização desta pesquisa, cujo objetivo foi investigar como 
ocorriam as experiências corporais e de movimento desses pequeninos na Educação Infantil. Para tal, procuramos analisar materiais e espaços físicos que possibilitassem o desenvolvimento deste trabalho e refletir sobre as formas de intervenção/prática pedagógica do professor nessas aulas.

\section{TRAJETÓRIAS DA PESQUISA}

A metodologia utilizada foi a pesquisa-ação, por permitir ao pesquisador fazer intervenções no contexto investigado, já que aulas de Educação Física para bebês não eram comuns na Escola de Educação Infantil da Rede Municipal do Município de Arroio do Meio, educandário em que ocorreu a pesquisa. Localizada na zona urbana, a escola atendia crianças de diversas classes sociais. A turma em que foi desenvolvido o estudo denominava-se Berçário A1 e era composta de dezesseis crianças cuja faixa etária variava dos cinco meses a um ano e seis meses.

Portanto, havia crianças que ainda exercitavam o equilíbrio para manterem-se sentadas, necessitando, em vista disso, de algum tipo de apoio; já outras, um pouco maiores, deslocavam-se pelo espaço disponível de diferentes formas. Cabe destacar que alguns bebês, nas primeiras intervenções, permaneciam o tempo todo no local em que eram colocados e, no encerramento da pesquisa, engatinhavam, e alguns até caminhavam.

O projeto de intervenção se constituiu de nove aulas semanais de Educação Física, com duração de trinta a quarenta e cinco minutos. O planejamento das ações teve sempre como elementos norteadores a rotina dos bebês na escola e as suas necessidades. Com essas aulas, o intuito era oferecer, a esses pequenos, atividades diferentes das que costumavam realizar cotidianamente na escola, desafiando-os a criar, inventar, descobrir e reelaborar movimentos e experiências corporais.

Como o objetivo era estimular a experimentação do corpo e do movimento, refletimos e planejamos os espaços em que poderiam ser desenvolvidas as práticas; questionamos os tipos e quantidade de materiais que disponibilizaríamos aos bebês; quais texturas, dimensões, tanto em relação aos espaços como aos materiais; e as atividades que eles seriam capazes de realizar.

As intervenções foram realizadas em diversos espaços da escola: salas com pisos quentes; materiais variados, como parque, laminado, tapete emborrachado; locais em que, nas paredes, havia espelhos grandes e corrimões. Já no pátio, a escolha incidiu sobre os lugares onde existiam brita, grama e alguns brinquedos de plástico permanentes. Os objetos oferecidos aos bebês foram os mais variados, como bolas grandes e pequenas, de variadas texturas e materiais; estrelas mágicas e coloridas ${ }^{3}$; animais da fazendinha; livros de manuseio infantil; chocalhos; túnel de lona e emborrachado; colchões de

3 Brinquedo infantil plástico de diversas cores, com 5 pontas, parecendo uma estrela. 
diversas espessuras e tamanhos; caminhões e carrinhos grandes; caixas de papelão; cestos de plástico; lençol e balões coloridos de diversos tamanhos.

As ações foram planejadas e adequadas ao contexto do grupo, sempre pensando em contemplar atividades que expressassem o que as crianças sentiam, desempenhavam e as capacidades que já haviam desenvolvido ou novos desafios. Ademais, o objetivo era envolver todos os bebês, sem preocupação com a técnica e precisão de movimentos, mas com a realização de tarefas que estimulassem a liberdade de ação e a criatividade. Pesquisar crianças nessa faixa etária exigiu bastante atenção, auxílio das professoras, afetividade e comunicação clara. É importante destacar que procuramos sempre respeitar os limites individuais de cada criança.

\section{BEBÊS EM MOVIMENTO: OPORTUNIDADES PARA EXPERIMENTAR}

Durante a realização das atividades, consentimos que os bebês se expressassem e movimentassem livremente, concedendo-lhes a oportunidade de estabelecerem relações consigo mesmos, com os colegas, as professoras, os materiais e o ambiente. Gonçalves (2010, p. 57) afirma que "quanto mais a criança for estimulada a vivenciar experiências novas e apropriadas para sua faixa etária, tanto maior e melhor o seu desenvolvimento". A autora acrescenta que a estimulação leva o indivíduo a experimentações concretas e significativas, permitindo que ele manipule e se aproprie do meio em que está inserido, comunicando-se consigo mesmo, organizando-se e desorganizando-se, para assim chegar à construção de uma base que o estruture como sujeito.

Ao organizarmos as aulas de Educação Física para os bebês, consideramos algumas particularidades, como a abertura para que eles pudessem descobrir, de modo independente, formas de se relacionarem com os materiais, isto é, experimentassem a novidade (material), as facilidades e as dificuldades desse diálogo, a liberdade para modificarem e transformarem suas ações a partir do diálogo com o material com o qual estavam interagindo. Os brinquedos oferecidos foram importantes elementos de conexão das crianças com o ambiente e colegas com quem compartilhavam as aulas.

Tal liberdade dava às crianças condições de construírem seus próprios conceitos. As atividades, organizadas de forma a levá-las a desafiar e a interagir com os materiais disponíveis, permitiam-lhes deles se apropriarem e manuseá-los da maneira que desejavam. As aprendizagens aconteciam a partir de sua própria experimentação corporal. O corpo sendo visto como parte do ato educativo, capaz de receber e transmitir conhecimento (VARGAS, 1999).

O processo de ensino e de aprendizagem na Educação Física não se restringe a exercícios voltados a certas habilidades e destrezas, mas também como um meio de capacitar o sujeito a refletir sobre suas possibilidades corporais e, com autonomia, exercê-las de maneira social e culturalmente significativas (BRASIL, 1998). Santin 
(1987, p. 34) afirma que "o movimento humano pode ser compreendido como uma linguagem, ou seja, como capacidade expressiva”. A Educação Física, neste sentido, não necessita ser baseada na técnica, na mecânica, no treinamento físico, mas fundamentarse nas experiências e vivências do corpo em movimento, que são fundamentais e únicas na vida de cada ser. Dessa forma, pode torná-la mais humana e basear-se em processos criativos do corpo.

Ao iniciar as práticas de intervenção, tivemos a preocupação de desenvolver atividades que, imaginávamos, seriam desafiadoras às crianças e diferentes das de sua rotina. $\mathrm{Na}$ aula/intervenção inaugural, primeiro contato direto com os bebês, foram desenvolvidas atividades com bolas.

O desafio colocado aos bebês foi que explorassem, da forma que conseguissem e imaginassem, bolas de diferentes cores, tamanhos e texturas. À medida que a aula foi se desenvolvendo, percebemos que as crianças perdiam o interesse pelo material. $\mathrm{O}$ fato nos levou a reuni-lo; que, além de tudo, estava muito disperso. Assim, concluímos que havia a necessidade de interagir mais com elas, instigá-las a realizar algo novo. A voz da professora, seu chamado claro e persistente, sua presença corporal e oferta em relação ao material se mostraram fundamentais para que os pequenos respondessem ao estímulo da exploração.

Ademais, constatamos que, ao iniciar a aula, é importante disponibilizar algum tipo de brinquedo como elemento de integração e interação inicial até o desenvolvimento da atividade propriamente dita. $\mathrm{O}$ brinquedo faz parte da realidade das crianças e, através dele, elas entram em contato com os outros e com o ambiente. Brougère (2008) afirma que o bebê já sabe se deseja ou não brincar. Quando não quer, chora; ao contrário, estica a mão, mexe a perna, dá um grito. Respeitar esse interesse, é fundamental. Além disso, faz-se necessário considerar o limite de cada um, a sua forma e ritmo de aprendizagem, características que levamos em conta durante a investigação.

Nas aulas seguintes, os bebês foram desafiados a explorarem colchões (subiram, desceram, pularam de diversas formas sobre e entre estes); túneis de lona e emborrachado (passaram por dentro, balançaram, apoiaram-se sobre os mesmos); bolas coloridas; livros de manuseio infantil e tapete emborrachado. Além disso, entraram em caixas de papelão, andaram em carrinhos grandes e sobre lençóis, sendo "puxados" pela pesquisadora no espaço em que se realizava a intervenção. Também exploraram cores, sons e texturas, em espaços abertos e fechados da escola, entre eles, a sala com espelhos e o pátio - onde havia brita e grama - com brinquedos grandes e permanentes.

Durante a pesquisa, ficou evidente que as crianças maiores interagiam mais com o espaço e materiais disponíveis, pois conseguiam se locomover pela sala, engatinhando, rastejando ou caminhando; já as menores permaneciam mais tempo sentadas e observavam com maior intensidade o que acontecia ao seu redor. Os balbucios estavam bastante presentes durante as intervenções, bem como o choro, sorriso, pequenos gritos, demonstrações de alegria e prazer em relação ao que era desenvolvido. Havia também uma busca frequente pelos materiais oferecidos e, para isso, locomoviam-se de 
variadas formas; os coloridos chamavam bastante a atenção dos pequeninos; além disso, se produziam algum som, maior ainda era o interesse. Alguns demoravam para iniciar a interação, enquanto outros logo saiam em busca de desafio e exploração.

\section{ORGANIZAÇÃO DO ESPAÇO E MATERIAIS}

Baecker (2001) propõe que as aulas de Educação Física na Educação Infantil partam das experiências de movimento em três âmbitos: a experiência corporal, a experiência material, a experiência de interação social. Os bebês, mesmo sendo muito pequenos, desde cedo, procuram e observam as outras crianças com olhares, expressando-se através de sorrisos e sons. Buscam, através do corpo, tocar o colega.

A organização do espaço que receberá os bebês é fundamental para que essas expressividades possam se manifestar. É importante que o ambiente escolhido para as aulas de Educação Física seja acolhedor, tranquilo e interessante. A disposição do material deve ser pensada com cuidado. E, à medida que as interações acontecem, o grupo pode ir transformando esse ambiente.

A primeira intervenção é a experiência que inicia a construção do contexto, que necessita ser bem pensada, elaborada e organizada, pois propicia o contato incipiente, e, através deste, o conhecimento e a interação com os bebês, seres tão pequenos, mas capazes de grandes atitudes e demonstrações.

O contexto frequentemente varia, haja vista a estrutura das intervenções ser sempre diversificada. $\mathrm{O}$ que pode variar nesse contexto é a organização do ambiente, o uso do tempo, a seleção e a oferta de materiais, a proposta de atividades e a reação das crianças. Durante o estudo, observamos que, a cada material e espaço disponibilizados, reações das mais diversas apareciam, como o deslocamento pelo espaço, a busca pelos materiais/atividades, pelo som que poderiam produzir os materiais e a escolha pelos mais coloridos.

Foi-nos possível observar que, em ambientes mais livres, como o pátio, as crianças permaneciam por um determinado tempo manuseando os materiais disponibilizados, mas, paulatinamente, começavam a se deslocar pelos espaços mais ociosos. Nos mais fechados, como a sala de aula, elas também se locomoviam; porém, dispersavam mais o material e, assim, precisavam buscar o que mais lhes interessava ou chamava a atenção. Barbosa (2010, p. 08) afirma que:

[...] uma das tarefas principais de um professor de bebês é criar um ambiente onde as crianças possam viver, brincar e serem acompanhadas em suas aprendizagens individualmente e também em pequenos grupos. Os ambientes precisam ser coerentes com as necessidades das crianças, proporcionando situações de desafio, mas também oferecendo segurança. 
Ao organizarmos a sala para os bebês, pensávamos sempre em oferecer espaços confortáveis, seguros, tranquilos e que pudessem auxiliar no apoio e sustentação das crianças e de seus movimentos. Acima de tudo, nossa intenção era transformá-los em ambientes prazerosos, bonitos, relaxantes, alegres e descontraídos.

A mbientes bem pensados e adequados incitam os bebês à curiosidade, exploração e busca de brinquedos, materiais e colegas, o que lhes possibilita escolher, ter e estimular a sua própria autonomia. Barbosa (2010 p. 08) sustenta que "as crianças pequenas, especialmente os bebês, têm a árdua tarefa de compreender e significar o mundo e precisam de tempo para interagir, para observar, para usufruir e para criar". A tarefa da criança de interagir com o que está a seu redor é bastante ampla e necessita de tempo.

\section{CHORO, RISO, BALBUCIO...: EXPRESSÕES DE BEBÊS EM MOVIMENTO}

Outra questão é que, muitas vezes, a professora imagina ter uma proposta muito interessante a oferecer aos bebês, mas eles (ou alguns) não participam da aula ou de parte dela. Há sempre um que está com sono; outro que precisa de um cuidado específico. $\mathrm{O}$ tradicional modelo de aulas em que a turma inteira participa da mesma atividade durante todo o tempo é fadado ao fracasso quando se trata desses pequeninos. São muito singulares as formas de "aproveitar", experimentar e usufruir o tempo e o espaço, e as crianças têm o direito de encontrar na escola e nas aulas de Educação Física um lugar para viver suas peculiaridades. Neste sentido, é tarefa do docente despertar na criança o desejo de realizar e produzir o novo, observando até onde ela pode chegar.

Nas intervenções realizadas, a cada aula, surgiam reações diferentes. Em alguns dias, as crianças estavam em maior número; às vezes, mais tranquilas; outras, mais agitadas. Ademais, se o estado de saúde ou físico do bebê apresentasse alguma alteração, esta interferia diretamente no seu brincar. Cabe relembrar que, durante a pesquisa, os limites de cada criança e sua forma de participação sempre foram por nós respeitados e constituintes do que se construía durante as aulas. De acordo com Falkenbach (1999, p. 71), "a escuta do professor deverá estar atenta a esses comportamentos, pois são componentes ricos que o auxiliam a interagir de forma eficiente".

As atividades eram desenvolvidas de modo que, primeiramente, as crianças fizessem a exploração da sua forma e, em seguida, houvesse a intervenção da pesquisadora, sendo introduzidos os desafios, a busca do que não havia sido manuseado, realizado, desenvolvido, com o intuito de levar os bebês a irem além do que já eram capazes de realizar.

As intervenções possibilitaram que as crianças mostrassem sua capacidade; o que aprenderam a realizar por meio dos desafios; a sua forma de analisar e o que contribuiu para essa nova maneira de explorar. Subir em obstáculos mais altos; sacudir objetos até que estes produzissem algum tipo de som; rolar; pular; rastejar; engatinhar eram 
"novidades". Cada movimento e objeto manuseado de forma diferente representava uma alegria imensa.

Nas intervenções realizadas durante as aulas, as emoções e expressões estavam sempre presentes. Estas aconteciam diante de cada material oferecido, atividade proposta, espaço ou comportamento da pesquisadora, dos colegas de grupo ou das professoras que acompanhavam as aulas. As crianças manifestavam isso de forma nítida e natural. Demonstravam seu interesse, o gosto ou não em relação ao que lhes estava sendo proposto/oferecido através de balbucios, risos, choros, pequenos gritos, movimentos de alguma parte do seu corpo ou produção de algum som diferente.

Sabemos que as emoções estão diretamente ligadas aos nossos pensamentos e vontades; procuramos sempre relacionar nossas necessidades e práticas ao que nos dá prazer. Isso nos autoriza a aludir que o professor pode ter dificuldades em perceber os sentimentos expressados pelos seus alunos, talvez pelo número destes em uma aula, ou que compõem o grupo.

Martins (2004 p. 91) nos explica que:

As coisas importantes na vida tornam-se importantes porque foram amplificadas pelo sistema emocional e nós as sentimos como importantes. A emoção intensificada não só nos faz prestar atenção ao que a despertou, mas também cria a motivação e força para a ação necessária.

Assim, pudemos perceber a importância das emoções e dos balbucios sempre presentes durante as aulas/intervenções. Era a maneira encontrada de a criança demonstrar as suas sensações e percepções sobre o que ocorria ao seu redor, com o seu corpo e o espaço onde ela se encontrava. Foi emocionante e significativo observar a espontaneidade de seres humanos tão pequenos. Sentimentos de alegria, raiva, nojo, medo, tristeza, surpresa se manifestavam através do franzir da testa, dos olhos que arregalavam ou fechavam, da boca que tremia ou fazia beiço, do sorriso que mostrava alguns dentes ou apenas a gengiva. Havia comunicação transmitida pelo corpo; um dito na ausência das palavras.

\section{CONSIDERAÇÕES FINAIS}

O trabalho corporal é fundamental nos primeiros anos de vida. Através dele, a criança, desde bebê, inicia a sua comunicação com o meio. Durante as aulas/ intervenções investigamos como poderia ser realizado este estudo de experiências corporais e de movimento de bebês na Educação Infantil, constatando a importância das atividades /desafios durante esse processo. O certo é que o assunto deveria ser tratado com seriedade, dando atenção a essas crianças, que, embora tão pequeninas, são capazes de grandes atitudes, demonstrações, superações e gestos. Esse contexto parece ser simples; entretanto, é muito amplo e exige um olhar especial. 
Acreditamos que algumas reflexões e discussões acerca do assunto merecem uma atenção maior no sentido de desafiar as escolas a saírem do tradicional, a mudarem esse contexto, a contemplarem o trabalho corporal, os desafios, a observarem as manifestações dos bebês. Além disso, faz-se necessário analisar o trabalho do professor inserido nesse meio, o que pode ser mudado e o que tem sido feito para isso.

É imprescindível que se pense e se elabore melhor os espaços, tornando-os adequados às intervenções, bem como os materiais que podem ser disponibilizados. Ademais, deve-se evitar de oferecer apenas coisas prontas; isso implica elaborar atividades fora da rotina tradicional, compreender a intervenção/prática pedagógica do professor inserido nesse meio, que é o ponto de referência dos bebês.

\section{REFERÊNCIAS}

BAECKER, I. M. "Vivência de movimento e Educação Física”, in: I Seminário Municipal de Lazer, Esporte e Educação Física Escolar, Santa Maria/RS. Anais... Santa Maria: Secretaria Municipal de Educação, 2001.

BARBOSA, M.C. As Especificidades da Ação Pedagógica com os Bebês. Ago. 2010. Disponível em: <http://portal.mec.gov.br/index.php?option=com_docman\&task=doc_ download\&gid=6670> acesso em: 21 mai. 2015 .

BRASIL. Ministério da Educação e do Desporto. Referencial Curricular Nacional para a Educação Infantil. Brasília: Secretaria de Educação Fundamental, 1998.

BROUGÈRE, G. Brinquedo e Cultura. 7. ed. São Paulo: Cortez, 2008.

FALKENBACH, Atos P. A Relação Professor/Criança em Atividades Lúdicas. Porto Alegre: Suliane-Editografia Ltda, 1999.

FONSECA, V. Desenvolvimento psicomotor e aprendizagem. Porto Alegre: Artmed, 2008.

GONÇALVES, F. Psicomotricidade e Educação Física quem quer Brincar põe o dedo aqui. São Paulo: Cultural RBL, 2010.

MARTINS, J. M. A lógica das emoções: na ciência e na vida. Petrópolis: Vozes, 2004.

SANTIN, S. Educação Física: uma abordagem filosófica da corporeidade. Ijuí: Unijuí, 1987.

VARGAS, A. L. S. Educação Física e o Corpo: a busca da identidade. Rio de Janeiro: Sprint, 1999. 